\title{
Corneal dellen in the limbal approach to rectus muscle surgery
}

\author{
HOWARD H. TESSLER AND MARTIN J. URIST \\ From the Motility Clinic, University of Illinois Eye and Ear Infirmary
}

Work in the Motility Service of the University of Illinois Eye and Ear Infirmary gave a clinical impression that there was a greater incidence of corneal dellen after the limbal approach to strabismus surgery than after the direct approach. The purpose of this study is to determine whether this impression is statistically valid.

The limbal approach to rectus muscle surgery has recently enjoyed popularity because of minimal trauma, easy access to the muscle, and reduction in scar tissue (Cortes, 1962; Massin and Hudelo, 1962; von Noorden, 1968). Proponents of the limbal approach have found few complications and one stated that the incidence of corneal dellen actually lessened with the limbal approach (von Noorden, I968).

\section{Method}

We reviewed all 170 cases of horizontal rectus muscle surgery that had been carried out during the years 1969 and 1970 at the University of Illinois Eye and Ear Infirmary. All surgery was performed by residents and it had been their decision whether to use the limbal or nonlimbal approach. The resident had also determined the suture type for both the muscle and conjunctiva. Altogether 14 different residents performed the surgery.

Surgery on 168 muscles used the limbal approach, and on 184 muscles the nonlimbal approach. All but five of the nonlimbal approach operations were done by direct over-the-muscle incision into the conjunctiva; the five exceptions used the Parks' fornix incision (Parks, 1968). There was little variance in muscle sutures: $4-0$ chromic catgut was used in 81 per cent of the limbal approach operations and in 84 per cent of the nonlimbal. In all others $5^{-0}$ chromic was used except for two patients for Address for reprints: Dr Howard H. Tessler, Motility Clinic, University of Illinois Eye and Ear Infirmary, 1855 West Taylor Street, Chicago, Illinois 60612, USA whom 6-o chromic was used. The conjunctiva was closed in 95 per cent of all cases, using 6-o chromic or plain catgut.

The Table shows the general findings of a 6.5 per cent dellen incidence with the limbal approach and a $2 \cdot 2$ per cent incidence with the direct or nonlimbal approach. This was significant to the 5 per cent level of confidence but not the I per cent level of confidence by the $\chi^{2}$ test. The majority of dellen occurred in resections and only one of the 15 was associated with a recession. Only two dellen of the total 14 occurred when $5^{-0}$ chromic was used.

\section{Comments}

Dellen were first described by Ernst Fuchs (IgII) as saucer-like excavations at the corneal margin. They are caused by swelling at the limbus like that occurring after a rectus muscle advancement.

Adalbert Fuchs (1929) noted that dellen had probably escaped attention because of their relative transparency and limbal location.

Our study, like all retrospective studies, has the weakness that these postoperative patients were not specifically studied for dellen. A prospective study would be better but difficult to carry out, considering the problem of adequate slit-lamp examination in the postoperative child. Furthermore, since most dellen appear and disappear rapidly, daily slit-lamp examinations are desirable in these children (DukeElder and Leigh, 1965). All the dellen noted in this study were large, significant dellen that could be noted grossly with a hand light. Undoubtedly, some dellen were missed. However, we believe the study to be accurate for large dellen.

The significant occurrence of dellen in the limbal approach operation as opposed to the nonlimbal approach is at variance with the results of von

Table

\begin{tabular}{|c|c|c|c|c|c|c|c|}
\hline \multirow[b]{2}{*}{ Approach } & \multicolumn{2}{|l|}{ Recessions } & \multicolumn{2}{|l|}{ Resections } & \multicolumn{2}{|l|}{ Total } & \multirow[b]{2}{*}{ Dellen $\%$} \\
\hline & No. cases & No. dellen & No. cases & No. dellen & Cases & Dellen & \\
\hline Limbal & IOI & I & 67 & 10 & I 68 & I I & 6.5 \\
\hline Nonlimbal & 98 & 0 & 86 & 4 & 184 & 4 & 2.2 \\
\hline
\end{tabular}




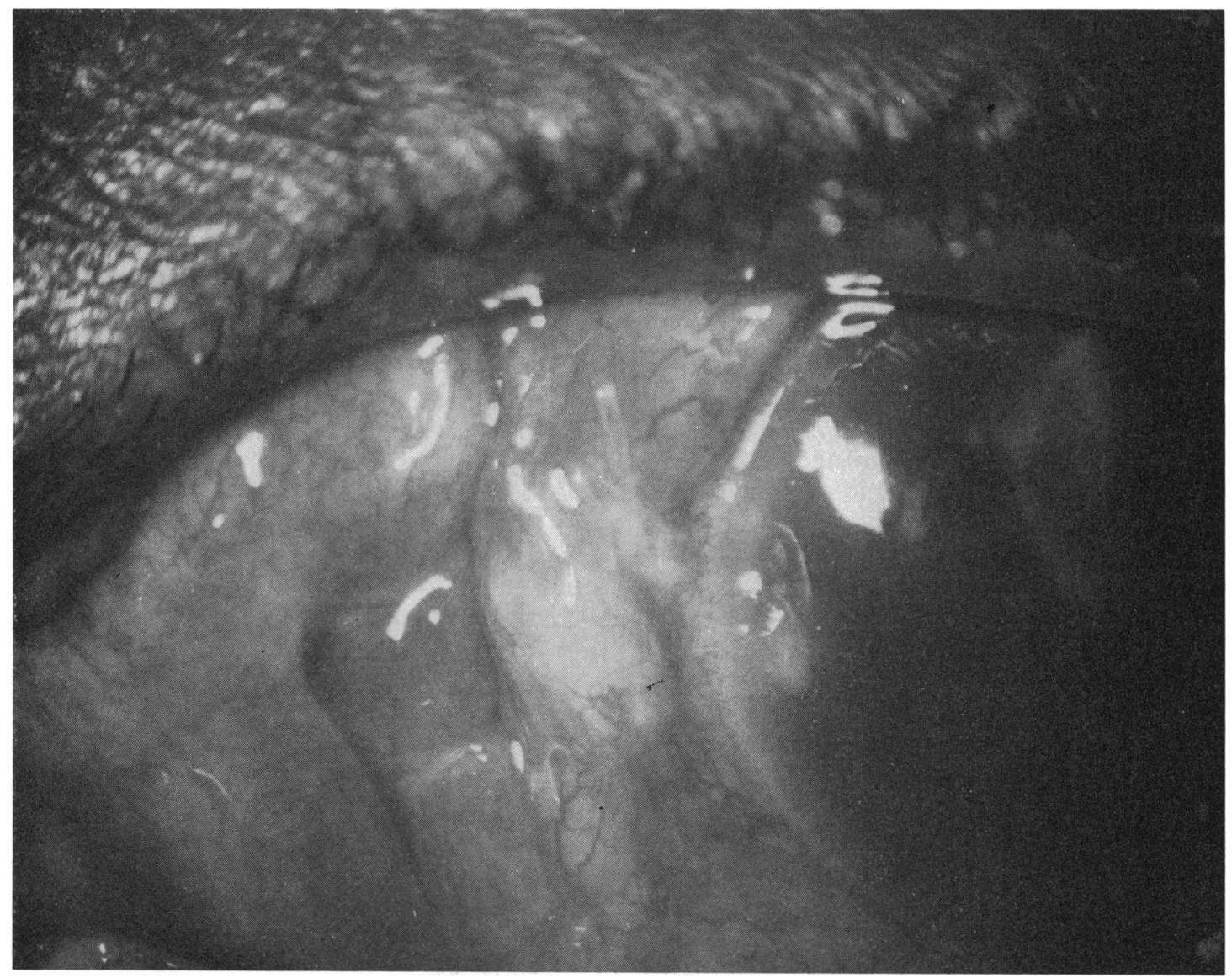

FIGURE Corneal dellen next to limbal elevation-secondary to strabismus surgery

Noorden (1968). He stated that the incidence of dellen decreased with the limbal approach and he observed only two dellen in 600 eyes operated on by the limbal technique.

The results of our study are, however, compatible with the theory of corneal desiccation as the cause of dellen (Norn, I969). Elevation caused by tissue damage and suture reaction at the limbus lessens the massaging and spreading action of the lids on the tearfilm. A limbal approach would logically seem to cause more desiccation than the more remote nonlimbal approach. The fact that resections resulted in more dellen than recessions also lends credence to this reasoning, as resections result in more tissue nearer the limbus than do recessions. Furthermore, it is possible that lack of vascular nourishment may also play a part in the development of dellen (Grayson and Keates, 1969). The peripheral cornea is nourished in part from the limbus (Hogan, Alvarado, and Weddell, 1971). The greater interruption in the limbal vasculature with the limbal approach may also contribute to the development of dellen, as it may in certain peripheral corneal inflammations (Aronson, Elliott, Moore, and O'Day, 1970).

We do not feel that this increased incidence of dellen necessitates the abandonment of the limbal approach. The incidence of 6.5 per cent is not too alarming. The sequelae of dellen tend to be benign (Fuchs, I9II; Fuchs, 1929; Duke-Elder and Leigh, 1965; Nauheim, 1962; Vancea, Vaighel, and Vancea, 1960) although they can lead to permanent vascularization and scarring (Baum, Mishima, and Boruchoff, I968). In fact, one patient in our present series developed bilateral bacterial ulcers at the sites of dellen. It is possible that carefully trimming the limbal conjunctiva so that it lies flat against the limbus would eliminate these dellen. von Noorden (1972) stated that eliminating bunching and thickening at the limbus reduced the incidence of dellen to nil.

The limbal approach provides a good, clean anatomical approach to the muscle and produces little noticeable conjunctival scarring. These benefits indicate that the limbal approach should not be abandoned. Surgeons should, however, be alert for 
postoperative dellen when using the limbal approach. This is especially true in a resection. We hope this knowledge will promote finer attention to surgical technique and consequently diminish the incidence of dellen.

\section{Summary}

A retrospective study of $\mathrm{I} 70$ cases of horizontal rectus muscle surgery performed during the years 1969 and 1970 at the University of Illinois Eye and Ear Infirmary revealed a 6.5 per cent incidence of dellen with the limbal approach to the muscle and a $2 \cdot 2$ per cent incidence of dellen with the nonlimbal or direct approach to the muscle. This was significant to the 5 per cent level of confidence by the $\chi^{2}$ test.

We feel that this finding of an increased incidence of dellen with the limbal approach complements the current theory of desiccation as the cause of corneal dellen.

We do not recommend abandonment of the limbal approach to rectus muscle surgery because of this finding, but suggest that surgeons scrutinize more carefully their postoperative patients for dellen. If dellen do occur careful trimming of the conjunctiva to avoid bunching and thickening may perhaps eliminate them.

\section{References}

AROnSON, s. B., elliott, J. H., MOORE, T. E., JR., and o'DAy, D. M. (1970) Amer. F. Ophthal., 70, 65 baum, J. L., mishima, s., and boruchoff, s. A. (ig68) Arch. Ophthal. (Chicago), 79, 657

CORTES, M. (1962) Arch. Chilenos Oftal., 19, 54

DUKE-ELDER, S., and LEIGH, A. G. (I965) 'System of Ophthalmology', vol. 8, pt. 2, p. 868. Kimpton, London

Fuchs, A. (1929) Amer. F. Ophthal., 12, 877

FUCHS, E. (I 9 I I) v. Graefes Arch. Ophthal., 78, 82

GRAYSON, M., and keATES, R. H. (I969) 'Manual of Diseases of the Cornea', p. 18. Little Brown, Boston

hogan, M. J., Alvarado, J. A., and Weddell, J. E. (I97 I) 'Histology of the Human Eye', p. I I4. Saunders, Philadelphia massin, M., and hudelo, J. (I962) Ann. Oculist. (Paris), r95, 995

NAUHeim, J. s. (1962) Arch. Ophthal. (Chicago), 67, 708

NORN, M. s. (1969) Acta ophthal. (Kbh.), 47, 88 I

PARKs, м. м. (1968) Amer. 7. Ophthal., 65, 907

vancea, P., Vaighel, v., and vancea, P. P. (1960) Ann. Oculist. (Paris), 193, 28

von NOORDEN, G. K. (1968) Arch. Ophthal. (Chicago), 80, 94

(1972) Personal communication 